This item was submitted to Loughborough's Institutional Repository (https://dspace.lboro.ac.uk/) by the author and is made available under the following Creative Commons Licence conditions.

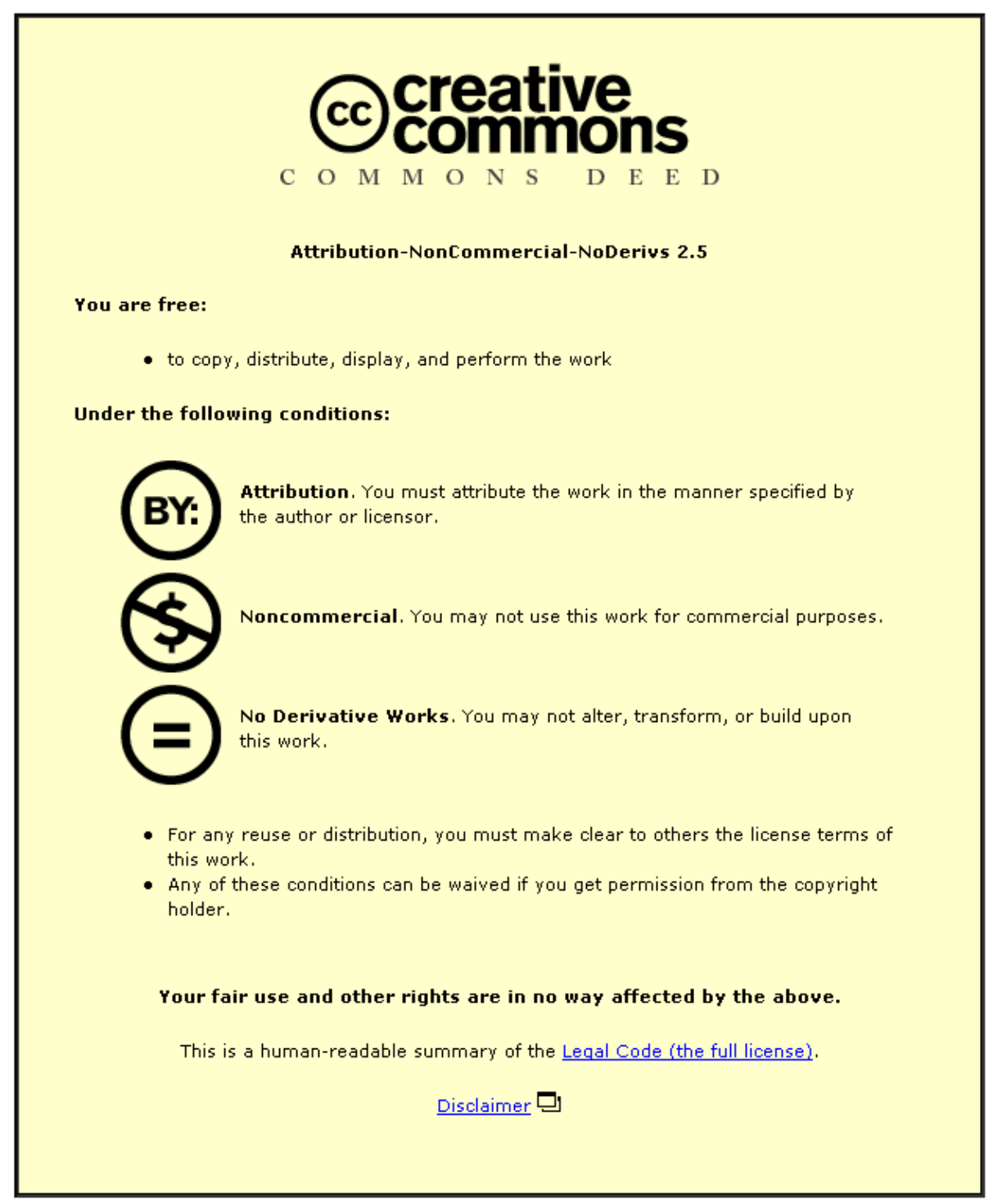

For the full text of this licence, please go to: http://creativecommons.org/licenses/by-nc-nd/2.5/ 


\section{Chapter 6 Epidemiological Approaches to Investigating Causes of Occupational Falls}

\section{Tim Bentley and Roger Haslam}

\section{8/2/05}

[UK English spelling to be retained]

\subsection{Introduction}

This chapter deals with slip, trip falls (STF), on the level or on steps and stairs, occurring in the workplace. As with other types of accidents, occupational STF are generally complex events. If we wish to understand the causes and identify the most effective means of prevention of this widespread source of work-related injury, detailed investigation and analysis of factors beyond the simple foot-floor interface is necessary. An ergonomics (systems) approach to understanding STF requires the collection and analysis of information relating to a range of individual, equipment, task, environmental and organisational factors that may contribute to the risk of occupational falls.

This chapter considers approaches to investigating occupational STF at the population level. A major study undertaken by the authors, examining STF among Royal Mail workers in the UK, is used to illustrate epidemiological approaches to understanding STF causation and prevention (Bentley, 1998; Bentley and Haslam, 1998; Haslam and Bentley, 1999; Bentley and Haslam, 2001). The first section of the chapter describes the use of descriptive epidemiology in the identification of patterns and trends in archival STF records, and the 
proximal causes of STF incidents (ie. those factors which contributed immediately before or at the time of the event). An example of a prospective approach to the collection of data on the immediate causes of accidents, the accident modelling system MAIM, is also presented in this section. The second section describes more detailed investigative approaches, complimentary to descriptive epidemiology. These are beneficial in providing further contextual (eg. organisational, motivational, cultural) information about STF risk in an organisation, and the identification of distal causal factors (ie. latent failures, Reason, 1990) contributing to or underlying STF occurrence. Focused accident-independent survey research and detailed incident follow-up investigation approaches are presented to illustrate how this information may be collected.

\subsubsection{Falls in the Royal Mail}

At the time the study commenced in 1994, outdoor falls to postal workers represented the largest cause of injury and lost-time within the delivery function of the Royal Mail, comprising nearly $30 \%$ of reported injuries and over 35\% of lost-days. Royal Mail estimated the cost of STF nationally to be approaching $£ 3$ million annually in direct costs alone. Moreover, injuries to Postal Delivery Officers (PDO) are not conducive to employee satisfaction and are disruptive to productivity at the local delivery office level. A major safety priority for the Royal Mail was, therefore, to identify why STF occurred in such numbers, and effective countermeasures to reduce their incidence.

A high proportion of postal delivery work in the UK takes place on foot. PDO must contend with a range of environmental risk factors during the course of their work, with hazards widespread on customers’ premises (Royal Mail delivers mail to the customer’s front door) and on public roads and pavements. The relatively uncontrolled nature of the PDO's working 
environment makes conventional STF prevention measures largely redundant in the mail delivery context. Examples from the Royal Mail study are used extensively in this Chapter to illustrate the application of epidemiological approaches to the investigation of falls.

\subsection{Epidemiological Approaches: Archival Data Analysis}

Where STF accident analysis is concerned with the identification of patterns of work-related STF in terms of who is being injured, where, in what circumstances, and when, descriptive epidemiological methods are used. Descriptive injury epidemiology involves two main activities (Cryer, 1995):

i. the description of patterns and trends in occupational injury rates by person (eg. age, sex, ethnic group), place (eg. location of accident, region) and time

ii. the identification of the causes (or contributory factors) of occupational injury, including both human and environmental factors

Descriptive injury epidemiology has the goals of identifying injury causes, priority areas for preventive action and evaluation of countermeasures designed to reduce incidence. This method of investigation is concerned primarily with the proximal causes of accidents (ie. those contributory factors immediately preceding the event) (Cryer, 1995).

Various sources of archival data may be available to aid STF investigation. In most FirstWorld countries, national data is available in the form of official government occupational health and safety statistics, hospital discharge or emergency records, coroner's data (fatalities), research organisation databases and so on. Most companies also maintain accident reporting databases. These company databases vary considerable in terms of usefulness of information collected. The analysis of data on PDO STF contained in the Royal 
Mail accident database is presented to illustrate the uses and limitations of descriptive epidemiological methods and data contained in a typical company database. The aims of the analysis were to:

i. identify features of the physical and ambient environment commonly present in delivery STF

ii. identify temporal patterns and trends in STF incidence

iii. determine patterns of STF incidence across the PDO population

iv. identify activities at the time of the accident

v. identify the most common events initiating STF incidents

vi. identify knowledge gaps and further research needs

\subsubsection{Method}

The database contained information on 1734 delivery STF cases reported between April 1993 and March 1994 in the Midlands division of the Royal Mail. Variables available for analysis (Table 6.1) were typical of company databases, and included each accident-involved employee’s personal and employment details, details of accident and injuries sustained, time and date, and length of absence from work. A 'one-line' narrative description of accident circumstances was also available for each case. Each delivery STF record was manually checked, and erroneous cases (ie. those that were not STF related) discarded. Cases with significant amounts of missing information were also withdrawn from the analysis.

Narrative text fields have been acknowledged as important for identifying specific hazards and other aspects of accident circumstances that might otherwise be missed (Stout, 1998). As a result of pilot sampling it was determined that the narrative text provided sufficient information in the majority of cases to allow coding for the following variables: 
i. PDO activity at the time of the STF incident

ii. Fall initiating event (FIE) (ie. slip, trip)

iii. Underfoot hazard related to fall

A coding form was produced from the pilot exercise and the narrative text was examined for each case with codes attributed for categories across the above variables. Coding was possible for some $86 \%$ of cases ('activity'). Once coded, the data were subject to simple frequency distribution, cross-tabulation and chi-square analysis, using SPSS.

Table 6.1. Information maintained on Royal Mail's accident database

\begin{tabular}{|c|c|}
\hline Information available for each case & Examples \\
\hline 1. Accident-involved PDO's delivery office & Leicester North; Woodhouse \\
\hline 2. Cause of accident & 'outdoor fall’; ‘stepped on’ \\
\hline 3. Function & Delivery; processing \\
\hline 4. Incident date & $20-6-93$ \\
\hline $\begin{array}{l}\text { 5. Absence from work (start and end date and total } \\
\text { days absent) }\end{array}$ & 20-6-93 to 23-6-93; 3 days \\
\hline 6. Nature of injury and body part injured & Sprain/strain; ankle \\
\hline 7. Incident time & 0700 \\
\hline 8. Age of involved PDO & 39 years \\
\hline 9. Sex of involved PDO & Female \\
\hline 10. Length of service of involved PDO & 13 years, 3 months \\
\hline $\begin{array}{l}\text { 11. 'One-line' narrative text field describing accident } \\
\text { circumstances }\end{array}$ & $\begin{array}{l}\text { 'the employee slipped and fell while walking down } \\
\text { an icy driveway'; 'the PDO fell down stairs leading } \\
\text { to the front door' }\end{array}$ \\
\hline
\end{tabular}




\subsubsection{Example Results}

A total of 1734 delivery STF cases were distributed across the two years of the analysis: 825 for 1993/4 (incidence rate: 80.4 per 1000 PDO) and 909 for 1994/5 (incidence rate: 88.5 per 1000 PDO). The majority of these incidents did not require a full day's absence from work (61\%). More than 3 days absence was required in 25\% of cases, and over 3 weeks in $9 \%$ of cases, confirming that serious injuries are not uncommon for STF occurring during mail delivery work.

\subsubsection{Activity, fall initiating event and surface condition or hazard}

Table 6.2 gives the distribution of delivery STF by activity of the accident-involved PDO immediately prior to the STF, the fall initiating event (FIE), and underfoot hazard leading to any slip or trip.

The most common activity was walking on the level between delivery points, although it is uncertain as to how many of these cases may have involved slopes, as steep slopes or inclines were rarely mentioned in the narrative text. Slipping was the most common FIE, accounting for $50 \%$ of delivery STF. The proportion of slips is likely to be higher, however, due to the large proportion of unclassified cases. Icy and wet surfaces were the most common underfoot hazards for slipping cases. Tripping was involved in $24 \%$ of delivery STF, with three major underfoot hazards identified: uneven ground, obstacles and kerbs.

Almost one-fifth of the delivery STF occurred while ascending or descending steps, with a slip being the most frequent FIE for step falls (61\%). The accident-involved PDO either tripped or missed a step in $15 \%$ of cases. 
Table 6.2. Distribution of delivery STF by activity, FIE and underfoot hazard

\begin{tabular}{|c|c|c|c|c|c|}
\hline $\begin{array}{l}\text { Activity of PDO immediately } \\
\text { prior to STF }\end{array}$ & $(\%)$ & $\begin{array}{l}\text { Fall Initiating Event } \\
\text { (FIE) }\end{array}$ & $(\%)$ & Underfoot hazard & (\%) \\
\hline \multirow[t]{3}{*}{ Walking on the level } & 63 & Foot slipped & 49 & $\begin{array}{l}\text { Ice } \\
\text { Snow } \\
\text { Wet surface or grass } \\
\text { Leaves } \\
\text { Loose surface/surface } \\
\text { movement }\end{array}$ & $\begin{array}{r}46 \\
17 \\
24 \\
6 \\
6\end{array}$ \\
\hline & & Foot tripped & 27 & $\begin{array}{l}\text { Uneven ground } \\
\text { Obstacles } \\
\text { Kerb } \\
\text { Wall/fence }\end{array}$ & $\begin{array}{r}35 \\
28 \\
28 \\
9\end{array}$ \\
\hline & & $\begin{array}{l}\text { Trod in/stepped on } \\
\text { Unclassified }\end{array}$ & $\begin{array}{r}5 \\
19\end{array}$ & & \\
\hline $\begin{array}{l}\text { Walking on steps (ascending or } \\
\text { descending) }\end{array}$ & 19 & $\begin{array}{l}\text { Foot slipped } \\
\text { Foot tripped/missed step } \\
\text { Other/unclassified }\end{array}$ & $\begin{array}{l}61 \\
15 \\
24\end{array}$ & & \\
\hline Climbing in/out of vehicle & 3 & & & & \\
\hline Climbing on/off bicycle & 1 & & & & \\
\hline Unclassified & 14 & & & & \\
\hline
\end{tabular}

In the absence of severity details for delivery STF injuries, days absent from work (days-lost) was used as a proxy. The distribution of FIE by days-lost is indicated in Figure 6.1. PDO more often incurred an injury requiring over 3 days absence from work following a fall on steps (35\% over 3 days) compared to PDO who had slipped or tripped on the level. Over 21 days absence was also most common for step falls (10\%), suggesting PDO are more likely to both fall (allowing for exposure) and sustain a serious injury when ascending or descending steps.

The distribution of FIE by body part injured was also considered. Ankle (23\%), knee (17\%) and back (16\%) were the body parts most often injured in delivery STF incidents. Figure 6.2 
shows the back was the body part most frequently injured for slipping FIE, while the ankle and knee were more commonly injured for trip and step falls.

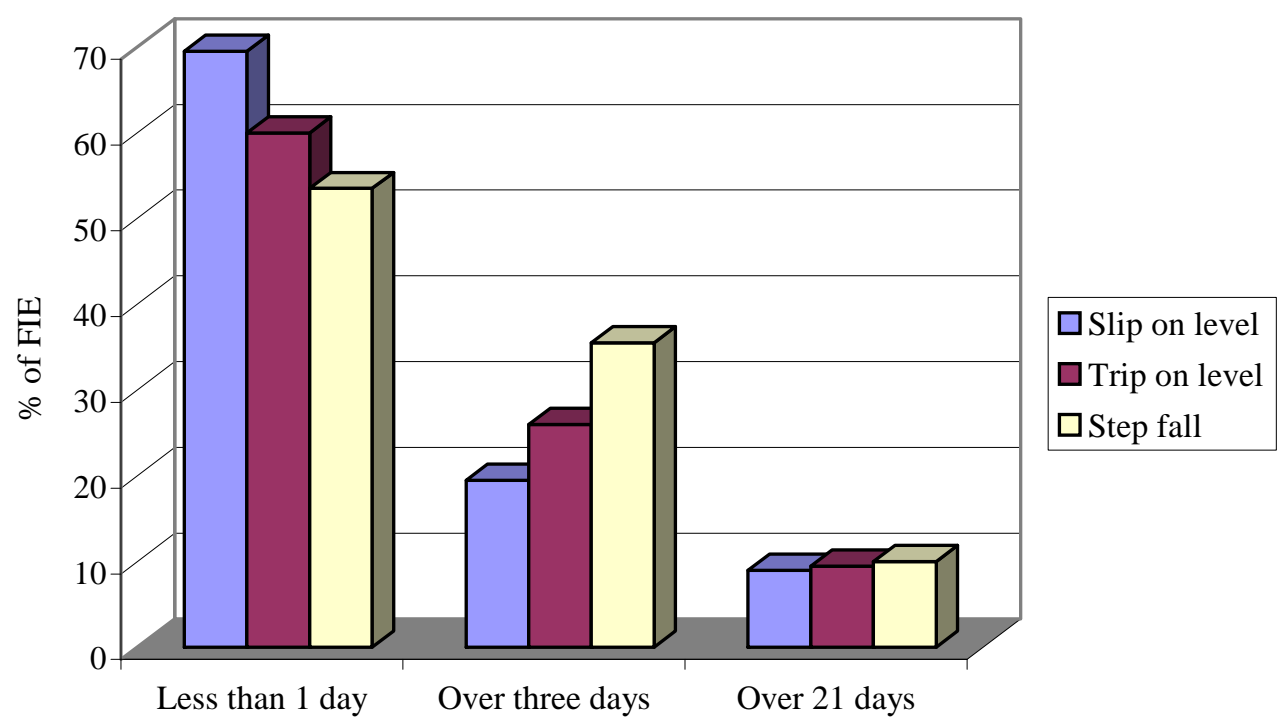

Figure 6.1. Distribution of FIE by days-lost

\subsubsection{Temporal analysis of delivery STF}

The distribution of delivery STF by month and time of day were considered to determine the impact of seasonal and temporal factors on STF incidence. Figure 6.3 gives the distribution of delivery STF by month. 


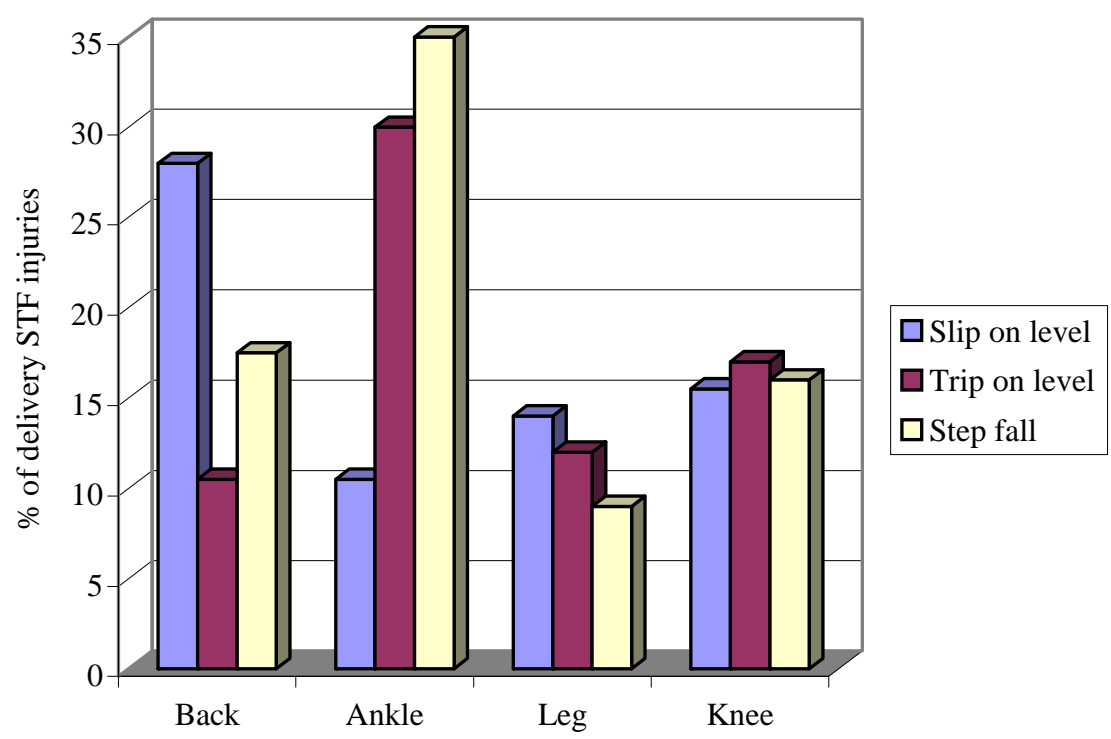

Figure 6.2. Distribution of delivery STF injuries by FIE and body part injured

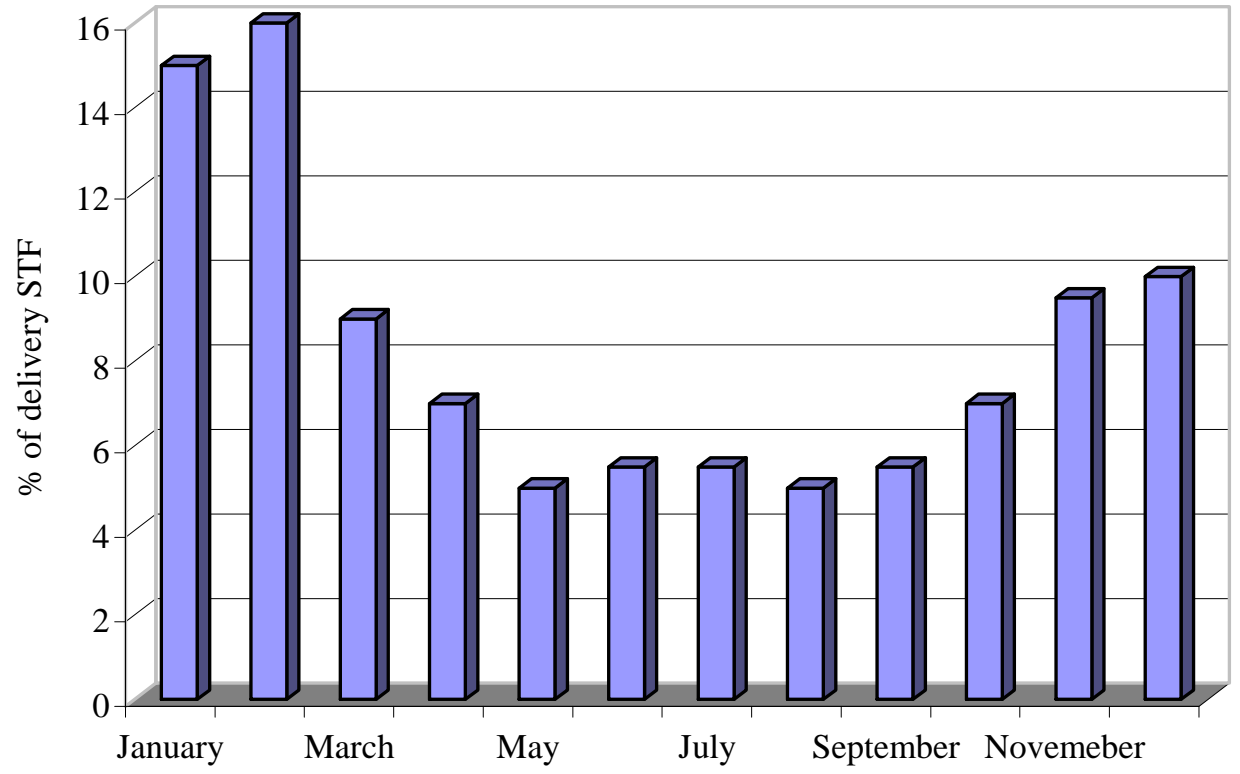

Figure 6.3. Distribution of delivery STF by month 
The 'U' shaped distribution of delivery STF across the calendar year suggests these falls are subject to seasonal variation and winter weather. Indeed, one-half of delivery STF occurred during the four-month winter period November to February.

Further analysis highlighted the impact of winter weather conditions on delivery slip incidents. Analysis of FIE by month showed $88 \%$ of slips where snow was the underfoot hazard occurred during the month of February (February 1994 + February 1995), with some 80\% of snow slips reported during February 1994. A similar cluster effect was identified for ice slips (the most common underfoot hazard in slipping cases). Large proportions of ice and snow slips were found to be concentrated into single days during the winter months.

\subsubsection{Sex of accident-involved PDO}

Incidence rates per 1000 PDO were calculated and are shown in Table 6.3 by sex and dayslost groupings.

Table 6.3. Two-year incidence rates (per 1000 employees) by sex for all reported delivery STF, and 3 and 21 days-lost STF cases

\begin{tabular}{llll}
\hline Days-lost & $\begin{array}{l}\text { Male incidence (per } \\
\text { 1000 employees) }\end{array}$ & $\begin{array}{l}\text { Female incidence } \\
\text { (per 1000 employees) }\end{array}$ & Significance \\
\hline $\begin{array}{l}\text { All delivery STF, regardless of } \\
\text { number of days-lost }\end{array}$ & 154.4 & 251.3 & $\mathrm{P}<0.01$ \\
Over 3 days-lost & 37.9 & 72.1 & $\mathrm{P}<0.01$ \\
Over 21 days-lost & 11.6 & 32.5 & $\mathrm{P}<0.01$ \\
\hline
\end{tabular}

Female PDO were found to have significantly higher incidence rates than their male colleagues for all reported STF, over 3 day and over 21 lost-days. These figures suggest females are more likely to experience falls and to suffer more serious injuries as a result. 
Further analysis revealed female PDO had approximately twice the incidence rate for trip falls than males, and were approximately 1.5 times as likely to slip or fall on steps.

\subsubsection{Discussion}

Slipping was the FIE in one-half of delivery STF, with highest occurrence of slip incidents occurring among older and female PDO. These findings are consistent with previous studies reported in the falls literature (eg. Lund, 1984; Buck and Coleman, 1985), where females and older workers have been found to have the greatest STF risk, although the evidence for these trends in other industries and countries is inconsistent. Slipping was the most common FIE for falls when walking on the level or on steps, and was the FIE in nearly all incidents that occurred while climbing in or out of a vehicle. Step falls are also a major concern, with slips on steps (25\% of all delivery STF) a high risk for PDO when the relative exposure to steps as opposed to level ground is taken into account. These figures suggest the interventions likely to be most effective in reducing delivery STF incidence are those designed to reduce the risk of slipping. Furthermore, the large proportion of slips occurring on ice and snow suggests anti-slip interventions should focus on these risk factors. This is further evidenced by the clustering of ice and snow falls on a small number of days over the period of the analysis, suggesting minimising exposure to adverse environmental hazards on these days carries the greatest potential for delivery STF prevention.

Tripping was the FIE in approximately one-quarter of cases, with the major underfoot hazards associated with tripping found to be uneven ground (eg. raised paving slabs), obstacles (eg. building materials, toys) and kerbs. These findings are in line with previous occupational STF studies (eg. Andersson and Lagerloff, 1983) and research concerned with falls among pedestrians in a public place (eg. Fothergill et al, 1995). It can be argued that a large 
proportion of underfoot hazards for both slipping and tripping are avoidable, especially those on householders' premises such as uncleared snow, ice from washing vehicles, toys, building materials, missing handrails for steps, broken footpaths and other debris and rubbish.

\subsubsection{Usefulness and limitations of epidemiological approaches in fall investigation research}

The analysis presented above has demonstrated the potential for epidemiology approaches, using analysis of data on a relatively large number of accident cases, to direct attention to key areas of risk. From the analysis of delivery STF, it was possible to determine incidence rates for different population groups, when STF were occurring across the day, week and year, and the body parts most susceptible to injury. It was also possible to indicate the seriousness and cost of injuries (based on days-lost).

Researchers and safety professionals have often failed to proceed beyond this level of analysis, however, running the risk of failing to identify key risk factors and potential interventions to target these. Through the analysis of narrative text fields in the accident database, the delivery STF study was able to determine the relative contribution of slip, trip and step falls to STF incidence, together with details of underfoot hazards involved in many of the STF cases. Moreover, it was possible to cross-tabulate these with other variables such as month and day of accident to provide detail on the pattern of weather-related occurrence. The finding that ice and snow-related slip cases clustered around a relatively small number of days per year was an important (if not entirely surprising) finding, and suggests countermeasures should be focused on reducing exposure to adverse environmental conditions on the days the hazards are present in a particular area. 
A further advantage of the descriptive epidemiological approach is the ability to consider patterns and trends in accidents over time. In the case of the delivery STF study, patterns of STF across the day, week and year were considered to useful effect. While the delivery STF analysis only considered data for a two-year period, other studies in which the authors have been involved have been able to examine trends for STF over several years. This can be useful for fall investigation for a number of reasons:

i. if the impact of annual weather conditions on STF incidence is of interest

ii. where it is necessary to establish the effect of environmental, workplace, behavioural or organisational change on STF incidence over time

iii. in experimental intervention research (eg. comparing baseline and post-intervention data)

Chapter 9 on STF accidents in the New Zealand logging industry provides a good example of the use of surveillance data in the evaluation of countermeasures for STF prevention at a national level.

Epidemiological approaches also have their limitations. For this reason it is argued that complementary methods should be used to assist in the interpretation of findings, providing further detail on risk factors, and to examine the contribution of distal factors, including behavioural and organisational influences.

Limitations of descriptive epidemiological approaches are primarily that:

i. they are dependent on the use of secondary data, with the quality and usefulness of the analysis therefore limited to the quality and quantity of the data that has been collected and collated ('rubbish in-rubbish out') 
ii. data may be subject to bias and error at various stages, including problems with reporting (eg. false reports, inaccurate accounts, poor memory of events); recording (eg. biased attributions of blame, misclassification - a 'fall' may be recorded as a 'struck against' event if the employee fell and hit their head on a wall); analysis and interpretation (bias to fit the investigators' model or philosophy or inaccuracy, error and poor judgement in content analysis and coding of narrative data)

iii. analysis typically yields only limited detail on risk factors, and the context in which these risks were present

iv. the influence of distal causes and underlying management and organisational factors in STF remain unknown or must be inferred

Some of these limitations (i and iii above) are, to a large extent, addressed through the use of prospective approaches to STF epidemiology, where the STF investigator is able to exert control over the type of information collected about fall events and the analysis the data then affords. One such method is discussed briefly below.

\subsection{Prospective epidemiological methods for investigating STF}

A prospective approach to the collection of data on the proximal causes of STF involves the development and use of modelling systems such as the Merseyside Accident Information Model (MAIM) (Davis et al, 2001a) and the Swedish ISA database (see Andersson and Lagerlof, 1983; Kemmlert and Lundholm, 1998). The MAIM system has been used to collect information about a wide range of accidents in the UK Merseyside region, using a computerbased diagrammatic representation of the sequences of events in incidents, from the first unforeseen event through to an event causing injury (Figure 6.4) (Davis et al, 2001a). Data is 
collected through accident victim interviews, using an 'object-verb-object' notation, through which interviewees are presented with a set of questions and corresponding menus of options that, once selected, are recorded directly in the computer database. The software is programmed so that the interviewee's responses determine future questions. MAIM then structures the accident data so as to facilitate subsequent causal analysis.

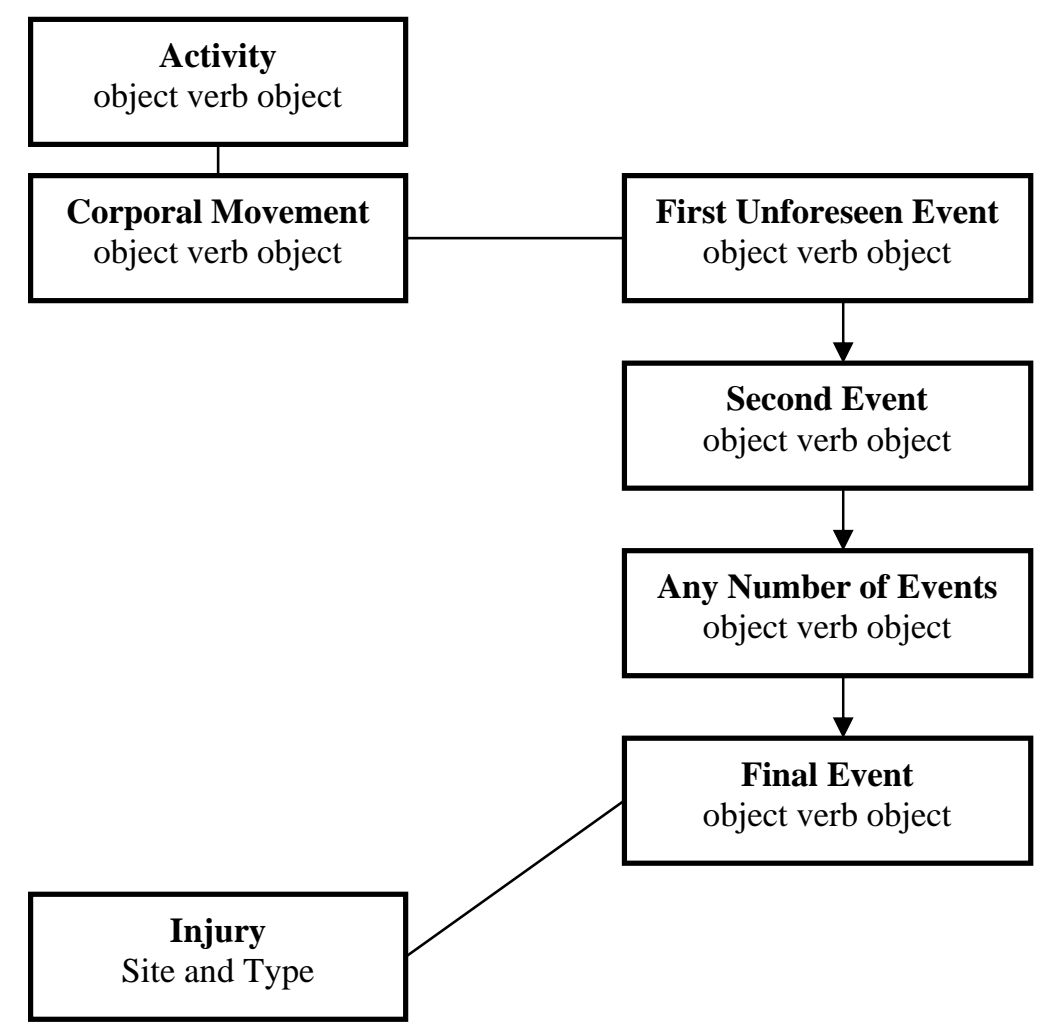

Figure 6.4. MAIM accident model (redrawn from Davis et al, 2001a)

Using a prospective approach to data collection, such as with MAIM, has the distinct advantage over archival data analysis of allowing researchers to collect predetermined detailed information on the events and proximal causes associated with STF. Moreover, the use of a computer model provides considerable power and flexibility in hypothesis testing, and ease of statistical analysis, allowing complex relationships between variables to be 
examined. Large datasets can be handled, and both cohort and case-control (eg. comparison of STF risk factors with those for other accident types) study designs can be undertaken. Recent findings from MAIM analyses have confirmed significant associations between carrying items and fall occurrence (Davies et al, 2001a) and falling on steps due to missstepping when wearing bifocal/varifocal spectacles (Davies et al, 2001b). In the later case, the analysis was undertaken following suggestions from researchers (eg Howarth et al, 2000) that wearing bifocal/varifocal spectacles on stairs might increase risk of falling (see also Chapter 4).

\subsection{Methods and techniques complimentary to descriptive epidemiology}

Beyond employing archival data analysis and prospective accident recording systems, such as MAIM, STF research can benefit from use of other qualitative methods to maximise understanding of the presence and role of STF risk factors in a given situation. This section considers two further forms of primary research, both of which have the general purpose of allowing a better understanding of the role of key risk factors identified through epidemiological approaches. Of particular interest are the influence and impact of distal or latent factors, and the organisational context in which STF accidents occur. Firstly, accidentindependent survey methods are described, including the use of interviews, focus groups and questionnaire surveys, involving a wide range of individuals drawn from the various levels of an organisation, Royal Mail in this instance. Secondly, the use of detailed accident follow-up investigations with STF involved employees is demonstrated. 


\subsubsection{Accident-independent survey methods}

\subsubsection{Questionnaire survey of PDO and Delivery Office Managers (DOM)}

A questionnaire was administered, comprising a small number of open questions seeking respondents' views on the following issues: unsafe conditions and acts associated with STF, training, attitudes to safety, managers' safety attitudes and activities, and ideas for reducing the incidence of delivery STF. A sample of PDO $(n=280)$ and all Midlands Delivery Office Managers (DOM) $(\mathrm{n}=50)$ were posted questionnaires. The response rates were 39\% (PDO) and 48\% (DOM) respectively.

\subsubsection{Interviews with safety personnel}

Semi-structured interviews were undertaken with 17 personnel responsible for safety, including safety managers and advisors, and local safety representatives. Information collected included details of safety training, training of new recruits, type and quality of footwear and PPE supplied, and management safety activities.

\subsubsection{Focus groups}

Three PDO focus groups were conducted, with between 8 and 12 PDO in each group, having a mixed range of experience in delivery work. One local safety representative was present at each meeting. Focus groups were held away from the work area, with participants given a list of issues for consideration and discussion with colleagues prior to the meetings. Information discussed within the three groups included: beliefs on why STF accidents occur; views on how STF might be avoided; safety attitudes and activities of employees and managers; use and quality of footwear and other equipment; and safety training provision and quality. 


\subsubsection{Overview of Results}

A large body of information relevant to the problem of delivery STF was generated through use of the accident-independent methods. Examples of the major findings are discussed under six headings below.

\section{Adverse weather conditions}

Adverse weather conditions were described as a major problem for PDO. In particular, snow and ice make it difficult to achieve performance targets as PDO have to progress more slowly in slippery conditions. PDO argued for greater time for deliveries on days where severe weather conditions are present. Slopes and steps leading down to houses were suggested as especially problematic, with householder's being understandably poor at clearing away snow and ice from their premises in the early morning.

\section{Poor walking surfaces}

Uneven paving, obstacles such as building materials and toys, and holes in walking surfaces were described as commonplace environmental risk factors. These being most often encountered on homeowners' property. Steps on older properties were indicated as especially hazardous, often lacking handrails.

\section{Footwear and equipment}

Safety managers and PDO expressed serious concerns about the type of footwear and frequency of issue to PDO. Much of the PDO's job is spent walking and the footwear provided was thought inadequate for such heavy use, with the tread wearing down rapidly. Snow chains, provided to PDO for working in snowy conditions, were reported as not used by the majority due to their ineffectiveness for most underfoot conditions. PDO described the 
chains as being uncomfortable to use on non-snow covered ground and dangerous on ice. Moreover, drivers could not wear chains because of the time required to put them on and take them off when leaving or entering their vehicle. Trolleys, designed as an alternative to carrying heavy mail pouches, were said to be underused. The main reasons for this being that trolleys slow PDO down and that they can not be used for walks with a high prevalence of steps or flats/apartment blocks. Heavy mail pouches were considered to present an additional risk of loss of balance as they are carried asymmetrically. Pouches were reported as particularly heavy on days where magazines have to be delivered. PDO suggested heavy mail items such as magazines should be delivered on less busy days of the week.

\section{Unsafe working practices}

The ‘job and finish’ policy employed by Royal Mail at the time of the study was thought by safety personnel and managers to motivate PDO to rush and take short-cuts and other risks. PDO themselves recognised this as a factor, and believed rushing on deliveries was a primary cause of STF accidents. PDO argued fast working as being necessary to achieve tight delivery time targets, while also agreeing the job and finish policy provided a strong incentive to hurry and take risks, including the carrying of overweight mail pouches.

The practice of reading and sorting mail for upcoming deliveries while walking was identified by all participants as an important risk factor. This behaviour reduces the ability of PDO to identify and avoid underfoot hazards. PDO noted this practice as widespread as it would take too long to stop and sort mail for the next delivery before walking to the next house. 


\section{Job training}

Training for new recruits was discussed as often restricted to 'on-the-job', involving the new recruit accompanying an experienced worker on their delivery route. Both employees and safety personnel believed this practice encourages the passing on of bad working habits such as the taking of short-cuts. Safety training was, apparently, not consistently administered to new recruits.

\section{Management and organisational factors}

All parties suggested performance, and in particular getting the job done quickly, as having priority over safety. The ‘job and finish’ policy and other organisational practices, such as the setting of delivery time targets and the turning of a blind eye to unsafe practices in favour of better productivity, were thought to be powerful influences on employee behaviour. These 'behaviour shaping practices’ were acknowledged to happen by participants from all levels of the organisation. Other management factors put forward as impacting on STF risk included the footwear policy and an absence of adverse weather procedures.

\subsubsection{Usefulness and limitations of accident-independent methods in fall investigation research}

The use of accident-independent survey methods provided fuller understanding of the risk factors identified from the earlier analysis of STF data. Specifically, additional information was derived from PDO on the risks associated with walking in slippery conditions, particularly on steep slopes and steps, and where different types of underfoot hazard are most frequently found. For instance, PDO identified householders' premises, particularly the path leading to the front door where the mail is delivered, as the most hazardous area for obstacles such as toys and building materials. Public pavements in poor repair were suggested to be commonplace, with uneven and broken paving a significant hazard for tripping. Information 
obtained on behavioural factors allowed the researchers to recognise the increased risk these underfoot hazards present where the tasks of walking and examining the mail for the next delivery (reading addresses and sorting mail) are undertaken in concert. Other unsafe practices identified by the research included rushing and the taking of short-cuts.

Through the use of these complimentary techniques it was possible to identify the underlying drivers of such unsafe behaviour and the barriers that would have to be overcome for preventative measures to succeed. Organisational policy such as 'job and finish’ and delivery targets were found to serve as 'behaviour shaping factors', motivating PDO to take risks implicated in STF causation. Other advantages of accident-independent investigations, as a complimentary method to epidemiological approaches, are those realised through the participatory involvement of workers who would be recipients of change as a result of the findings of the study. The need to understand the problem from the workers' perspective can not be overstated.

While the information produced from the accident-independent methods was of considerable value in improving understanding of the STF from a wider, systems perspective, it is desirable to maximise the objective basis for resulting conclusions and recommendations. The final section of this chapter outlines the use of detailed accident follow-up investigations as a form of triangulation with the methods discussed above.

\subsubsection{STF incident follow-up investigations}

If the published literature can be taken as a guide, detailed follow-up investigations as a means of identifying the causes of STF are rarely used. Reasons for this may be many, although the associated cost, practical and ethical difficulties may, in many instances, make 
the method unviable. Indeed, the problems involved in setting up such a study can be considerable, with issues to be addressed including: recruitment and access to a representative sample, the practicalities of being informed of accidents and making contact with potential interviewees, and the potential for non-response to bias the sample. The expense associated with such a study can be prohibitive, particularly if the sample is large and widely distributed. Many of these problems are less of an issue where the research is conducted in-house in an organisation, with employees of the organisation the subject of investigation.

In whatever context follow-up investigation STF research is undertaken, collection of high quality data will depend on having well designed and piloted systematic data collection tools, and the willing participation of the study group. The following section provides an account of detailed follow-up investigations undertaken as part of the Royal Mail study.

\subsubsection{Method}

Detailed interviews were undertaken with 40 STF involved PDO (Haslam and Bentley, 1998). The major purpose of the interviews was to examine the involvement of environmental, behavioural and organisational factors identified by the accident-independent methods described previously (section 6.4.1). The investigations took place as soon as possible after the accident was reported (mean interval: 9 days), and at the site of the accident. Respondents were asked to describe in detail the accident events, hazards involved, behaviour and equipment used. Additional questions concerned issues such as training and management safety practices. Accident events and contributory factors were recorded on an events and causal factors chart for each case investigated (Haslam and Bentley, 1999). 


\subsubsection{Results}

To illustrate the method, findings relating to three key areas of concern identified in accidentindependent investigations are presented: physical environment, footwear and equipment, and unsafe behaviour and work practices.

\section{General details}

Ages of involved PDO ranged from 19 to 56 years, with a mean age of 40 years, 6 months. Experience in job ranged from 1 week to 27 years, with a mean length of service of 9 years, 3 months. Some $22 \%$ of the PDO were female, this figure being representative of the $18 \%$ female PDO population in the Royal Mail Midlands Division at the time. The injured PDO fell and made contact with the ground in 85\% of cases, the remaining PDO making contact with the door of their van (8\%) or stumbled but avoided striking the ground (8\%). Injuries were most often to the ankle (35\%), most of which were sprains or 'twists', and to the knee and lower leg area (23\%), most of which were lacerations.

\section{Physical environment}

Underfoot hazards were most frequently snow (40\%) and ice or frost (30\%), reflecting the winter period of the study. Damaged paving was the hazard in $8 \%$ of cases. 'Avoidable' environmental hazards were involved in $23 \%$ of cases investigated, with most of these situated on householders’ property.

\section{Footwear and equipment}

Footwear worn at the time of the STF was inspected and the mean time used for delivery work recorded. The researcher's rating of the tread condition for Royal Mail issued shoes, where the PDO had slipped, was either 'very poor' (worn smooth, no tread) or 'poor' (little 
tread remaining) in 75\% of cases, although the mean age of the footwear was only 4 months. These findings support those of accident-independent investigations in which PDO and safety personnel argued footwear issued to PDO to be unsuitable for heavy use and winter conditions.

It was policy at the time of the study for snow chains to be available to PDO for use in snowy conditions. In none of the cases where slips occurred on snow $(n=16)$ were snow chains being worn at the time of the STF incident. Reasons given for not wearing snow chains were in line with those raised in the accident-independent investigations.

Where the mail pouch was being carried, it was at least three-quarters full in $40 \%$ of cases. In 3 cases, the weight appeared to have been instrumental in the PDO over-balancing and falling following a slip. Overweight pouches were being carried in 4 cases, while $77 \%$ of those who usually carried their pouches stated it was normal practice to carry overweight pouches. Again this finding supports those of accident-independent methods.

\section{Unsafe behaviour and work practices}

Table 6.4 provides a breakdown of unsafe behaviours and work practices identified as in common use by the accident-independent investigations. The proportion of STF involved PDO who reported using the practice at the time of the incident is shown, together with the proportion of PDO who stated they usually used the practice during the course of their work. Some $60 \%$ of PDO admitted to using some form of unsafe practice at the time of the STF. The majority of PDO accepted that using these practices probably increased their risk of having a fall. Reasons given for using these practices included time-saving, with wanting to

get home early, time pressures because of delivery targets and the need to catch a lift or public 
transport back the delivery office the main explanations. These findings supported those of the accident-independent investigations, where sorting mail while walking, rushing, and taking of short-cuts were suggested to be common practices.

\section{Risk factor interactions}

Among this sample of delivery STF incidents, a primary risk factor interaction was the presence of slippery underfoot conditions and the use of unsuitable and worn footwear. The combination of worn footwear, unsafe time-saving behaviour and slippery conditions was involved in $50 \%$ of cases investigated. A second important risk factor combination was the presence of a trip hazard and the practice of reading or sorting mail while walking.

Table 6.4. Use of unsafe behaviours and work practices

\begin{tabular}{lll}
\hline Unsafe behaviour or practice & $\begin{array}{l}\text { PDO using practice at time of fall } \\
(\%)\end{array}$ & $\begin{array}{l}\text { PDO who used practice during } \\
\text { normal working (\%) }\end{array}$ \\
\hline $\begin{array}{l}\text { Rushing (running, walking very } \\
\text { quickly) in slippery conditions }\end{array}$ & $33(\mathrm{n}=13)$ & $70(\mathrm{n}=28)$ \\
$\begin{array}{l}\text { Taking short-cuts (eg. climbing over } \\
\text { a wall/crossing a lawn) }\end{array}$ & 0 & $65(\mathrm{n}=26)$ \\
$\begin{array}{l}\text { Reading or sorting mail while } \\
\text { walking }\end{array}$ & $40(\mathrm{n}=16)$ & $85(\mathrm{n}=34)$ \\
$\begin{array}{l}\text { Jumping down steps/skipping steps } \\
\text { Jumping off a platform/vehicle }\end{array}$ & 0 & $25(\mathrm{n}=10)$ \\
$\begin{array}{l}\text { Cycle scooting } \\
\text { Carrying more than one pouch }\end{array}$ & $2(\mathrm{n}=1)$ & $10(\mathrm{n}=4)$ \\
$\begin{array}{l}\text { Total injured PDO using unsafe } \\
\text { practice at time of STF }\end{array}$ & $60(\mathrm{n}=24)$ & $20(\mathrm{n}=8)$ \\
\hline
\end{tabular}




\subsubsection{Discussion}

The brief overview of findings from follow-up investigations illustrates the advantages of primary data collection in addition to the use of archival information in the identification of risk factors for STF. Through the use of detailed investigations, even with a relatively small sample of cases, it was possible to expand on the information produced on proximal factors (individual, environmental, task-related), and furthermore, provide a more objective basis for the assertions regarding distal factors (eg. management and organisational influences on PDO work practices) which resulted from accident-independent investigations.

\subsection{Conclusions}

The triangulation of various accident-centred and accident-independent methods is of considerable value for those seeking to understand the causes of occupational falls at the population level. While many researchers and safety professionals rely on descriptive epidemiological methods alone, this chapter has argued that useful information, important to understanding the complex factors involved in fall accidents, may be missed where the sole source of evidence is archival accident data. The use of accident-independent investigations, such as surveys of the workforce, can provide information that assists interpretation of the findings of epidemiological work, provides organisational context to epidemiological findings, and identifies the role of distal factors in the accident chain of events. Detailed follow-up interviews provide objectivity, validity and reliability to the investigator's conclusions regarding the role of proximal and distal factors. These and other aspects to be considered when selecting epidemiological techniques for investigating STF are shown in Figure 6.5. 
Falls are complex events. Understanding the causes of occupational STF from an ergonomics perspective requires analysis of factors relating to the entire work system, their interaction, and underlying influences. The use of descriptive epidemiological approaches alone may fail to deliver this information, limiting progress towards recommendations for fall prevention.

\begin{tabular}{|c|c|c|c|c|}
\hline \multicolumn{5}{|c|}{ Data Collection Techniques for STF investigation } \\
\hline Archival data & $\begin{array}{l}\text { Individual } \\
\text { accident } \\
\text { reports and } \\
\text { records }\end{array}$ & $\begin{array}{l}\text { Prospectively } \\
\text { collected } \\
\text { computer- } \\
\text { based data }\end{array}$ & $\begin{array}{l}\text { Accident- } \\
\text { independent } \\
\text { survey } \\
\text { methods }\end{array}$ & $\begin{array}{l}\text { Detailed } \\
\text { follow-up } \\
\text { investigations }\end{array}$ \\
\hline
\end{tabular}

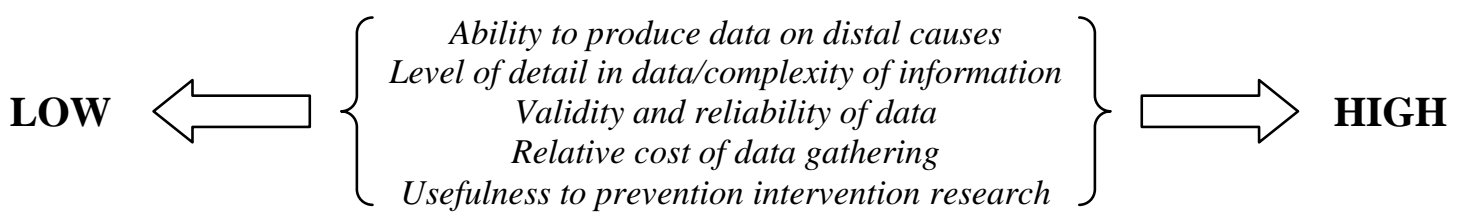

Figure 6.5. Data collection techniques for STF investigation, and their relationship to key research concerns 


\section{References}

Andersson, R. and Lagerlof, E., 1983, Accident data in the new Swedish information system on occupational injuries, Ergonomics, 26, 33-42.

Bentley, 1998, Slip, trip and fall accidents occurring during the delivery of mail. PhD. Thesis. Loughborough University.

Bentley, T. and Haslam, R., 1998, Slip, trip and fall accidents occurring during the delivery of mail. Ergonomics, 41, 1859-1872.

Bentley, T. and Haslam, R., 2001, A comparison of safety practices used by managers of high and low accident rate postal delivery offices. Safety Science, 37, 19-37.

Bentley, T. and Haslam, R., 2001, Identification of risk factors and countermeasures for slip, trip and fall accidents during the delivery of mail. Applied Ergonomics, 32, 127-134.

Buck, P.C. and Coleman, V.P., 1985, Slipping, tripping and falling accidents at work: a national picture. Ergonomics, 28, 949-958.

Cryer, C., 1995, The epidemiology of work-related injury. In: C. Slappendel (Ed), Health and Safety in New Zealand Workplaces (Palmerston North: Dunmore Press), pp 15-59.

Davies, J.C., Stevens, G. and Manning, D.P., 2001a. An investigation of underfoot accidents in a MAIM database. Applied Ergonomics, 32, 141-147. 
Davies J C, Kemp G J, Stevens G, Frostick S P and Manning D P, 2001, Bifocal/varifocal spectacles, lighting and missed-step accidents. Safety Science, 38, 211-226.

Fothergill, J., O’Driscoll, D., Hashemi, K., 1995, The role of environmental factors in causing injury through falls in public places. Ergonomics, 38, 220-223.

Haslam, R. and Bentley, T., 1999, Follow-up investigations of slip, trip and fall accidents among postal delivery workers. Safety Science, 32, 33-47.

Howarth P A, Hill L D, Haslam R A and Brooke-Wavell K, 2000, Falls on the stairs - visual risk factors. Optometry Today, June, 26-27.

Lund, J., 1984, Accidental falls at work, in the home and during leisure activities. Journal of Occupational Accidents, 6, 181-193.

Reason, J., 1990, Human Error (Cambridge: Cambridge University Press). 